\title{
¿Convivencia escolar y mercado educativo? Un análisis comparativo entre apoderados y estudiantes
}

\section{School coexistence and educational market? A comparative analysis between proxies and students}

\author{
KaRen CÁrdenas Mancilla* \\ PAULA ASCORRA COSTA*
}

En Chile, en 2011, se establecieron ocho indicadores de calidad educativa como respuesta a las fallas del sistema de educación instalado en los años ochenta. Estudios recientes plantean dificultades en la medición de uno de estos indicadores, el de clima de convivencia escolar, lo que afecta su comprensión dentro de las comunidades escolares. Este estudio se propuso abordar las percepciones de estudiantes y apoderados respecto a este indicador para las cohortes 2014-2018, y comparar los indicadores de estudiantes y apoderados según el tipo de escuela y cohorte. Para el análisis secundario se utilizó el ANOVA. Los resultados muestran diferencias en las percepciones entre apoderados y estudiantes, y diferencias significativas en las percepciones de apoderados conforme al tipo de escuela. Las percepciones de apoderados pueden explicarse mediante elementos socioculturales favorecidos por el mercado educativo chileno. En contraposición, la percepción de estudiantes parece vincularse a la propia experiencia escolar. Se concluye que la evaluación de la convivencia escolar en Chile debe avanzar hacia una evaluación diferenciada por actor educativo, y se cuestiona la construcción del indicador de clima de convivencia escolar, pues responde más a un mercado educativo que a la mejora de la calidad educativa.

\author{
Palabras clave: \\ convivencia \\ escolar, calidad \\ educativa, \\ indicadores de \\ calidad, indicador \\ de convivencia, \\ análisis de \\ varianza
}

Recibido: 19 de enero de 2021| Aceptado para su publicación: 25 de agosto de 2021| Publicado: 18 de octubre de 2021

Cómo citar: Cárdenas Mancilla, K. y Ascorra Costa, P. (2021). ¿Convivencia escolar y mercado educativo? Un análisis comparativo entre apoderados y estudiantes. Sinéctica, Revista Electrónica de Educación, (57), e1271. https://doi.org/10.31391/S2007-7033(2021)0057-014 
In Chile, in 2011, eight quality indicators were installed, which emerged as one of the responses to the failures of the educational system installed since the 1980s. One of these indicators is the "Climate of school coexistence". Recent studies have raised difficulties in its measurement, which may affect its understanding within school communities. This study aimed to analyze the perceptions of students and parents regarding this indicator for the 2014-2018 cohorts, and compare the indicators of students and parents according to the type of school and cohort. A secondary analysis was performed using ANOVA. The results show differences in perceptions between parents and students; and significant differences in the perceptions of parents according to the type of school. The perceptions of parents can be explained by sociocultural elements, which have been favored by the Chilean educational market. In contrast, students' perceptions seem to be linked to their own school experience. It is concluded that the evaluation of school coexistence should advance to an evaluation differentiated by educational actor. The construction of the indicator "Climate of school coexistence" used in Chile is questioned because it responds more to an educational market than to the improvement of educational quality.

\section{Keywords:}

school coexistence, educational quality, quality indicators, coexistence indicator, ANOVA

\footnotetext{
*Psicóloga. Magíster (c) en Estudios de Género y Cultura, mención Ciencias Sociales por la Universidad de Chile. Becaria ANID. Investigadora en la línea convivencia y bienestar escolar del Centro de Investigación para la Educación Inclusiva (SCIA-ANID 160009), de la Pontificia Universidad Católica de Valparaíso, Chile. Docente en la Escuela de Psicología de la misma universidad y profesional del proyecto FONDECYT 1191883. Líneas de investigación: convivencia escolar y profesionales de apoyo a la convivencia escolar. Correo electrónico: karen.cardenas@pucv.cl/https://orcid.org/00000003-2828-6824

** Doctora en Psicología por la Universidad de Chile. Académica de la Escuela de Psicología de la Pontificia Universidad Católica de Valparaíso, Chile. Investigadora principal en la línea de convivencia y bienestar escolar del Centro de Investigación para la Educación Inclusiva (SCIA-ANID 160009), e investigadora responsable del proyecto FONDECYT 1191883. Líneas de investigación: convivencia escolar, ciudadanía y bienestar escolar. Correo electrónico: paula.ascorra@pucv.cl/ https://orcid.org/0000-0001-9449-8273
} 


\section{INTRODUCCIÓN}

$\mathrm{D}$ esde los años ochenta, en Chile se comenzó una reforma educativa profunda, proceso que redefinió el rol del Estado como garante de derechos educativos, al instalar un nuevo sistema de gestión escolar a través de la figura de los sostenedores (administradores de establecimientos escolares), así como un nuevo sistema de financiamiento a las escuelas por medio del voucher por estudiante; también, se reestructuró y privatizó la educación superior. Así, dio inicio el denominado "mercado educativo chileno" (Assael et al., 2011; Slachevsky, 2015; Sanhueza, 2019).

Este mercado educativo se tradujo en la construcción de proyectos educativos privados, la posibilidad de lucro, y la instalación de un sistema de libre competencia entre escuelas (Assael et al., 2011; Slachevsky, 2015). Esta lógica se estableció junto con un sistema de medición de la calidad de la educación (SIMCE) que permitió "certificar los aprendizajes" a través de la evaluación anual de indicadores académicos con base en el supuesto de que los apoderados pudieran elegir "libremente" la escuela de mejor calidad (Cárdenas y López, 2021).

No obstante, la competencia se realizó en condiciones desiguales y se dieron mayores presiones para las escuelas municipales, las cuales se hicieron visibles en tres aspectos: el acceso a un presupuesto limitado e inestable a raíz del financiamiento vía voucher, el sometimiento a evaluaciones constantes, y la posibilidad de cerrar escuelas cuando las evaluaciones resultaran desfavorables (Ascorra et al., 2019). Esto impactó de modo negativo su calidad educativa.

El deterioro se hizo evidente en la queja masiva de estudiantes secundarios (enseñanza media en Chile), quienes se organizaron bajo el lema "educación de calidad para todos" en los reconocidos movimientos estudiantiles de 2006 y 2011. Como respuesta a las demandas estudiantiles, se promulgaron una serie de leyes, que dieron forma a lo que se conoce como un nuevo orden educativo (Herrera, Reyes-Jedlicki y Ruiz, 2018), cuyo eje central fue la mejora de la calidad de la educación.

Esta perspectiva de mejora toma como foco de intervención la escuela, en el supuesto que, cambiar la escuela y mejorar la calidad de sus procesos y docentes, podía revertir el problema en la calidad. Nacen, así, conceptos como "el valor agregado de la escuela", "quién dijo que no se puede" y "la escuela hace la diferencia" (Herrera, Reyes-Jedlicki y Ruiz, 2018). Sin embargo, esto se realizó sin alterar el orden social ni el mercado educativo.

De ese modo, el problema estructural de la segregación educativa y la desigualdad social se traslada a un plano menos conflictivo de controlar; nos referimos al espacio del aula y de la escuela a través de la medición y gestión del "rendimiento escolar", evaluado en pruebas estandarizadas e indicadores de calidad (Herrera, Reyes-Jedlicki y Ruiz, 2018).

Atendiendo a la necesidad de responder a una mejor calidad educativa, desde 2011 se integraron al SIMCE ocho nuevos indicadores, denominados "indicadores de desarrollo personal y social" (IDPS) (Ministerio de Educación de Chile, 2011). Los IDPS permiten incorporar una perspectiva más amplia de la calidad e incorporan dimensiones subjetivas para su análisis, como el clima y la participación escolar. Sin embargo, estos indicadores entregan una puntuación global 
que considera la perspectiva de apoderados, estudiantes y profesores, sin distinguir las percepciones que pueden existir entre ellos (Ministerio de Educación de Chile, 2013).

Desde la aparición de los primeros resultados de los IDPS, entregados por la Agencia de la Calidad de la Educación de Chile, se ha puesto atención a la baja calidad de la convivencia escolar de las escuelas municipales, en comparación con las particulares subvencionadas y privadas. Desgraciadamente, el indicador entrega un puntaje global de las percepciones de la escuela, y desconocemos si estudiantes de escuelas municipales perciben mejor o peor la calidad del clima respecto a las escuelas subvencionadas y privadas. Tampoco conocemos las percepciones de los estudiantes acerca de las que emiten sus apoderados.

Estudios nacionales e internacionales concluyen que lo más adecuado para las mediciones de clima escolar es considerar las percepciones de diferentes actores, pero analizarlas de manera desagregada. La investigación sostiene que las apreciaciones entre actores son muy distintas: mientras que los profesores se preocupan por su estabilidad laboral, desarrollo y transparencia de la gestión, los estudiantes tienen mayor interés en las relaciones de amistad (Deemer, 2004; Johnson, Stevens \& Zvoch, 2007; Torres-Vallejos, 2020) y los apoderados, en proporcionar a sus hijos ambientes seguros (libres de violencia, droga) y que otorguen las posibilidades de acceso a la universidad y, con ello, su desarrollo social (Canales, Guajardo y Orellana, 2020).

Con base en lo expuesto, nuestro trabajo se propone analizar y comparar el indicador de clima de convivencia escolar desagregado para estudiantes y apoderados de enseñanza básica y media (primaria y secundaria) en las cohortes de 2014 a 2018, según dependencia administrativa (escuelas municipales, subvencionadas y privadas). Responder a esta inquietud se vuelve relevante, pues permite hacer visibles las voces de estudiantes y apoderados, además de comparar estas voces de acuerdo con la dependencia escolar y cohorte. Esto ayuda a profundizar en la comprensión de la realidad educacional chilena y, con ello, generar evidencia concreta que apunte a la mejora de la calidad educativa. Finalmente, podemos cuestionar cómo actúan los indicadores educativos en la conformación de opinión pública, al iluminar y sesgar determinada información.

\section{LA CALIDAD EDUCATIVA COMO MEDIO DE REGULACIÓN DEL MERCADO EDUCACIONAL}

A partir de los años ochenta, en Chile, inició una reforma educativa que tomó como principios rectores los lineamientos propuestos por el grupo denominado los Chicagos Boys (Fuentes y Valdeavellano, 2015). Este grupo lo formaron egresados de las escuelas de economía nacionales que realizaron su posgrado en la Escuela de Economía de Chicago, y siguieron los planteamientos de Milton Friedman referidos al libre mercado.

La noción de libre mercado se basa en el principio de la oferta y la demanda como reguladora de los precios y potenciadora de la mejora de los bienes y servicios. Los principios anteriores se consagraron en la Constitución Política de la República de Chile, promulgada el 21 de octubre de 1980, en pleno periodo dictatorial. Esta Constitución cambió el rol del Estado, desde una noción de Estado de derecho a una de Estado subsidiario. De este modo, la Constitución estableció 
como verdad el dogma respecto a que "lo económico" está entregado a la libre iniciativa de los privados, quienes, por definición, serían más eficientes, y le reservó al Estado los espacios donde los privados eran ineficientes. Con esto se inaugura la noción de "Estado mínimo" para dar cuenta de una reducción del tamaño y poder del Estado a favor de los privados.

La Ley Orgánica Constitucional de Enseñanza (Ministerio de Educación de Chile, 1990) cambió el rol de un Estado docente a uno subsidiario, y el Estado debió financiar un sistema gratuito destinado a asegurar el acceso equitativo, inclusivo y sin discriminaciones arbitrarias a toda la población. Además, la misma ley estipula la "libertad de enseñanza", que se comprende como el derecho de abrir, organizar y mantener establecimientos educacionales, y el derecho de los padres de escoger el establecimiento de enseñanza para sus hijos. Así, la libertad de enseñanza en Chile no es la libertad de cátedra, sino la libertad de acceso de los privados al sistema educativo con financiamiento del Estado.

Así, la reforma educacional se alzó en consideración de cuatro pilares: la descentralización administrativa de los establecimientos de financiamiento público, conocido como proceso de "municipalización", lo que llevó a reducir el tamaño del Estado al traspasar la educación a las municipalidades; el financiamiento escolar vía voucher por estudiante; el proceso de privatización de la educación, que abre la posibilidad al lucro y la creación de escuelas privadas con financiamiento público; y la instalación de un modelo de mercado educativo bajo principios de libre competencia (Cornejo, 2006; Assael et al., 2011; Slachevsky, 2015).

Esta reforma al sistema escolar se consolidó para muchos en 1988 con la instalación del SIMCE, pionero para la época (Verger, Bonal y Zancajo, 2016). Vale la pena recordar que, para hacer competir a las escuelas y desarrollar un "mercado de educación" que permita el libre flujo de estudiantes de un establecimiento educacional al otro, se requiere una "medida de calidad educativa" que discrimine de manera "neutra" cuáles establecimientos son los mejores. Lo anterior, en el entendido de que aquellas escuelas que ofrecerían mejores ofertas educativas e indicadores de calidad educativa podrían competir por mayor matrícula escolar y un financiamiento más grande (Bellei \& Vanni, 2015).

En este contexto se comienza a discutir sobre la calidad educativa referida a mediciones y pruebas estandarizadas. Según Prieto (2019), existen dos enfoques sobre calidad. El primero de ellos corresponde a una racionalidad económica, que tiene como objetivo el desarrollo económico y la formación de capital humano para su consecución. Este enfoque apela a la evaluación y creación de indicadores que permitan constatar logros y resultados. El segundo enfoque apunta a una tradición humanista, en la cual se evalúan procesos y se concibe a la educación desde una perspectiva integral, que no puede reducirse a aspectos técnicos e instrumentales. Algunos autores han señalado que, en Latinoamérica, las políticas de calidad en educación se han instalado desde una tradición económica, específicamente desde la influencia de organismos como el Banco Mundial y la Organización para la Cooperación y el Desarrollo Económicos (OCDE) (Prieto, 2019; Anaya, 2019; Cavieres, 2014).

Existen múltiples estudios que han constatado los efectos de la instalación del sistema escolar chileno. Uno de los más sustanciales ha sido la alta segregación escolar. 
Según indicadores de la OCDE (2016), el sistema escolar chileno se posiciona como uno de los más segregados del mundo. Lo anterior supone la existencia de escuelas municipales (públicas) para estudiantes con bajo nivel socioeconómico o en situación de vulnerabilidad, escuelas particulares subvencionadas o fundaciones (de financiamiento mixto) para estudiantes de niveles socioeconómicos medios, y escuelas privadas para estudiantes de nivel socioeconómico alto (Bellei, 2013; Assael et al., 2011; Valenzuela, Bellei y De los Ríos, 2010; Cornejo y Redondo, 2007). Estas escuelas no solo se encuentran segregadas según condición económica, sino que también se asocian a peores o mejores indicadores académicos, lo que muestra una ventaja considerable para aquellos estudiantes que asisten a escuelas privadas (González, 2017; Cavieres, 2014).

\section{Necesidad de otros indicadores de calidad}

Durante 2006 y 2011, los movimientos estudiantiles posicionaron a nivel nacional la demanda por la calidad y equidad en la educación (Assael et al., 2011; Escobar, 2018; Córdoba, Laborda y Reyes, 2020). A la par, a escala internacional se levantaban discursos que apuntaban a nuevas concepciones sobre la calidad y que incorporaban elementos de aprendizaje transversal desde una perspectiva humanista (Prieto, 2019). De esta manera, se comenzó a demandar otra forma de comprender la calidad que considerara elementos contextuales y de aprendizaje transversal, como el desarrollo personal y social (Padilla y Rodríguez, 2019; Rodríguez-Garcés, Padilla-Fuentes y Suazo, 2020) desde una lógica top-down y bottom-up.

En este contexto, durante 2011 se promulgó en Chile la ley que creó el Sistema Nacional de Aseguramiento de la Calidad de la Educación (Ministerio de Educación de Chile, 2011). Esta ley estableció la figura de dos nuevas institucionalidades: la Agencia de Calidad de la Educación, cuya función principal es evaluar los logros de aprendizaje (SIMCE) e indicadores de calidad (IDPS), y la Superintendencia de Educación, cuya finalidad es fiscalizar el cumplimiento de la normativa (Ministerio de Educación de Chile, 2011, 2019).

La incorporación de los IDPS (autoestima académica y motivación escolar; clima de convivencia escolar; participación y formación ciudadana; hábitos de vida saludable; asistencia escolar; retención escolar; brecha de género y titulación técnico profesional), a cargo del Sistema Nacional de Aseguramiento de la Calidad de la Educación, constituyó un avance limitado en la medición de calidad, pues, a pesar de aportar una mirada más amplia, la suma de los IDPS contribuye solo en un 33\% a la evaluación global, y el 67\% restante corresponde únicamente a las evaluaciones de contenido curricular (Ministerio de Educación de Chile, 2011; Agencia de Calidad de la Educación, 2019).

En particular, la incorporación del indicador de clima de convivencia escolar se sustenta en tres aspectos: su gran incidencia en la calidad de vida y bienestar del estudiantado; su efecto moderador en las conductas de riesgo y conductas antisociales; y su relación con la mejora de aprendizajes cognitivos, que acrecienta sus resultados (Agencia de Calidad de la Educación, 2018). Estos tres aspectos señalados por la Agencia de Calidad derivan de diversas investigaciones en los ámbitos internacional y nacional (National School Climate Center, 2012; Cohen \& Geier, 2010; Berger et al., 2009; Rivers et al., 2009; Devine \& Cohen, 2007). 
A pesar de que la incorporación de los IDPS se constituye como un avance en la medición de la calidad, algunos autores han expuesto que estos progresos han resultado ser insuficientes. Al respecto, un estudio desarrollado por Ascorra y colegas (2019), que indagó diferentes políticas vinculadas a la convivencia escolar en Chile, expuso diferencias entre las definiciones de convivencia escolar y su medición. Este estudio constató que, mientras las conceptualizaciones de convivencia escolar apuntan a una perspectiva amplia, es decir, que consideran valores democráticos, inclusivos, sentido de pertenencia y abordan el conflicto, entre otros aspectos, su medición se posiciona desde una perspectiva estrecha y se restringe a un enfoque de seguridad y orden (Ascorra et al., 2019).

En esta misma línea, otro estudio reciente constató resultados similares, y evidenció una relación entre el indicador de clima de convivencia escolar (ICE) y la convivencia "pacífica", vinculada a la contención y erradicación de los conflictos y fenómenos de violencia (Ascorra et al., 2020a).

Otros estudios realizados con el ICE han constatado algunas diferencias según el tipo de actor evaluado, la pertenencia a establecimientos escolares de bajos ingresos y el nivel socioeconómico de las familias. Al respecto, Padilla y Rodríguez (2019) realizaron un estudio a partir de la reconstrucción del ICE de 2014 por actor en octavo y décimo grado. Cabe señalar que, hasta 2019, la Agencia de la Calidad de la Educación no entregaba los datos desagregados por actor educativo, ya que la ley se lo impedía, de ahí que los autores mencionados hayan tenido que "reconstruir el índice" al no poder trabajar con el real.

El estudio constató una peor percepción del indicador por parte de estudiantes, quienes puntuaron más bajo que sus apoderados y docentes en ambos niveles de enseñanza. Estas diferencias entre actores se atribuyeron a las distintas experiencias asociadas a cada actor (Padilla y Rodríguez, 2019). Asimismo, confirmó diferencias en las puntuaciones según la composición socioeconómica de la escuela. Así, las de menores recursos y que atienden a población vulnerable económicamente mostraron tener un clima de convivencia más perjudicial que a las que asisten estudiantes con mayor nivel socioeconómico. Lo anterior fue similar para estudiantes y profesores (Padilla y Rodríguez, 2019).

\section{Segregación escolar y elección de escuelas: ¿libre elección?}

En un contexto de alta segregación escolar y un "amplio" mercado educativo (Cornejo, 2006; Assael et al., 2011), surgen las interrogantes sobre las posibilidades y criterios que sustentan la elección de escuela. En este contexto, durante los últimos veinte años se han desarrollado diversas investigaciones en Chile que buscan comprender este fenómeno. Estos estudios, independientemente de sus particularidades entre sí, han expuesto que esta elección se sustenta ante todo en aspectos socioculturales (Canales, Guajardo y Orellana, 2020; Gayo, Otero y Méndez, 2019; Orellana et al., 2018; Carrasco, Falabella \& Mendoza, 2015), los cuales se diferencian de acuerdo con el nivel socioeconómico (NSE) de los apoderados.

En general, la literatura nacional se ha centrado en apoderados pertenecientes a un NSE medio (Canales, Guajardo y Orellana, 2020), los cuales presentan una mayor diversidad de oferta educativa (48\% de escuelas a nivel nacional; Ascorra, Cárdenas 
y Álvarez-Figueroa, 2020), pues tienen la opción de escoger entre distintas modalidades de escuela según lo que puedan costear. Estos apoderados han tenido preferencia por escuelas subvencionadas y, en menor medida, particulares (sin aporte del Estado). Esto se sustenta en la posibilidad de diferenciarse de ciertos estudiantes y familias que son percibidos como una amenaza para sus hijos e hijas debido a sus conductas violentas, delictivas o de riesgo (Córdoba, Laborda y Reyes, 2020; Canales, Bellei y Orellana, 2016). De esta manera, los apoderados de NSE medio valoran un ambiente escolar que promueva el orden y la seguridad. Asimismo, las escuelas subvencionadas ofrecerían protección y control social ante el riesgo de socialización con conductas percibidas como marginales (Canales, Bellei y Orellana, 2016).

Por otro lado, los apoderados de NSE perciben las escuelas subvencionadas en un rango de calidad media, que les permite acceder a una mejor educación conforme a lo que ellos pueden pagar. La calidad para estos apoderados es comprendida también como un concepto sociocultural, y escasamente se atribuye a indicadores cuantitativos como el SIMCE (Córdoba, Laborda y Reyes, 2020).

Los estudios sobre elección de escuelas que incorporan a apoderados de NSE bajo o alto han sido pocos. Lo anterior se confirma con la limitada oferta disponible para estos sectores. Los apoderados de NSE bajo han manifestado escasas posibilidades de elección debido a su condición socioeconómica, por lo que acceden a escuelas municipales (Córdoba, Laborda y Reyes, 2020; Orellana et al., 2018; Bellei et al., 2016). A pesar de ello, estudios como el de Córdoba, Laborda y Reyes (2020) han constatado algunas particularidades respecto a sus criterios de elección.

De este modo, los apoderados de NSE bajo han demostrado valorar aspectos como la cercanía física, la calidad humana de la escuela, el clima escolar, la seguridad de la escuela, el orden y disciplina, la permanencia del equipo docente, el vínculo con redes de la municipalidad (como acceso a salud, beneficios comunales), entre otros aspectos (Córdoba, Laborda y Reyes, 2020; Bellei et al., 2016). Por otra parte, estos apoderados, en general, tienden a autoexcluirse de escuelas más selectivas por temor al fracaso de sus hijos (Orellana et al., 2018; Bellei et al., 2016).

Cabe destacar, también, que la investigación demuestra que son las escuelas municipales las que reciben a los estudiantes con trayectorias educacionales distintas, ya sea porque han repetido, porque han sido expulsados de las escuelas o porque sus padres han decidido optar por otra oferta educacional. Esto ha ido construyendo un imaginario de "escuela sinfu", esto es, "escuela sin futuro", o bien, escuela "basurero", lo que denosta socialmente la labor que hace la escuela municipal (López et al., 2013; Raczynski y Muñoz, 2004).

En el caso de los apoderados de NSE alto, se ha expuesto una limitada oferta educativa atribuida a escuelas privadas de manera exclusiva, las cuales representan solo el 9\% del país (Ascorra, Cárdenas y Álvarez-Figueroa, 2020) y, además, han mostrado ser bastante homogéneas entre sí (Córdoba, Laborda y Reyes, 2020). Los apoderados de NSE alto valoran aspectos como acceder a un capital cultural similar o superior al de origen, a una red de contactos, al aprendizaje de una segunda lengua, entre otras características (Córdoba, Laborda y Reyes, 2020; Carrasco, Donoso y Mendoza, 2016; Gubbins, 2014). Otro aspecto valorado es la calidad educativa, entendida como la proyección de acceder a universidades prestigiosas (Canales, Guajardo y Orellana, 2020). 
Algunos estudios han permitido visibilizar una profunda relación entre la elección de escuela y la reproducción, consolidación o proyección de la clase social de origen (Orellana et al., 2018; Ball, 2003). Así, la escuela, y en particular la experiencia escolar, se vincula a la adquisición de marcadores culturales que sustentan y mantienen las diferencias de clase. Los apoderados pagarían por la experiencia social de la niñez y adolescencia en la escuela (Córdoba, Laborda y Reyes, 2020).

Considerando que las políticas educativas de segundo orden no han logrado revertir los procesos de reproducción de la desigualdad y han mantenido en Chile el "mercado educativo", se hace necesario analizar las percepciones de apoderados y estudiantes respecto al clima escolar. A partir de ello, este estudio tuvo un doble propósito: analizar las percepciones de estudiantes y apoderados respecto al ICE para las cohortes 2014-2018, y comparar las diferencias en el ICE según el tipo de escuela (dependencia administrativa) a la que pertenecen. Esto resulta relevante, pues, además, existe escaso conocimiento respecto al ICE (Padilla y Rodríguez, 2019; Rodríguez-Garcés, Padilla-Fuentes y Suazo, 2020; Ascorra et al., 2020b).

\section{MÉTOdo}

El estudio es de tipo descriptivo-correlacional (Hernández, Fernández y Baptista, 2010). Inicialmente se buscó analizar el indicador a nivel nacional y, en seguida, establecer comparaciones entre dependencias según el actor, nivel de enseñanza y año de evaluación.

\section{Participantes}

El muestreo tuvo un carácter censal y consideró como unidad a la escuela (Rodríguez, 1996). Participaron todos los establecimientos de dependencia municipal, particular-subvencionado y particular, evaluados en los IDPS de 2014 a 2018. Consideramos estas dependencias debido a que concentran la mayor cantidad de matrícula escolar (97.1\% en 2018), y, además, se encuentran consignadas en todos los registros correspondientes a este periodo.

La evaluación consideró a estudiantes y apoderados de los cuatro niveles de enseñanza (primaria y secundaria) en los que se aplica el SIMCE, esto es, cuarto básico, sexto básico, octavo básico y segundo medio (décimo grado), algunos de ellos evaluados alternadamente. No se incluyó a profesores, pues la Agencia de Calidad se reservó el derecho de confidencialidad y anonimato de estos actores (Secretaría General de la Presidencia de Chile, 2008). El total de establecimientos evaluados por nivel de enseñanza y año se expone en la tabla 1.

Tabla 1. Número de establecimientos participantes según dependencia y actor

\begin{tabular}{|c|c|c|c|c|c|c|c|c|c|c|c|c|}
\hline \multirow{2}{*}{ Año } & \multicolumn{4}{|c|}{ Municipal } & \multicolumn{4}{|c|}{ Particular subvencionado } & \multicolumn{4}{|c|}{ Particular } \\
\hline & IV & VI & VIII & $\mathrm{X}$ & IV & VI & VIII & $\mathrm{X}$ & IV & VI & VIII & $\mathrm{X}$ \\
\hline Estudiantes & $\mathrm{N}$ & $\mathrm{N}$ & $\mathrm{N}$ & $\mathrm{N}$ & $\mathrm{N}$ & $\mathrm{N}$ & $\mathrm{N}$ & $\mathrm{N}$ & $\mathrm{N}$ & $\mathrm{N}$ & $\mathrm{N}$ & $\mathrm{N}$ \\
\hline 2014 & 4024 & 4005 & 2847 & 678 & 3084 & 3042 & 2638 & 1621 & 400 & 396 & 400 & 372 \\
\hline 2015 & 3930 & 3894 & 2914 & 785 & 3054 & 3015 & 2625 & 1630 & 402 & 402 & 398 & 377 \\
\hline
\end{tabular}




\begin{tabular}{|c|c|c|c|c|c|c|c|c|c|c|c|c|}
\hline 2016 & 3904 & 3893 & - & 806 & 3015 & 2974 & - & 1628 & 419 & 415 & - & 387 \\
\hline 2017 & 3865 & - & 2939 & 823 & 2999 & - & 2611 & 1618 & 434 & - & 421 & 399 \\
\hline 2018 & 3684 & 3636 & - & 802 & 2933 & 2899 & - & 1578 & 484 & 478 & - & 444 \\
\hline Apoderados & & & & & & & & & & & & \\
\hline 2014 & 3954 & 3925 & 2840 & 676 & 3061 & 2997 & 2621 & 1617 & 400 & 393 & 399 & 372 \\
\hline 2015 & 3862 & 3834 & 2909 & 785 & 3026 & 3001 & 2621 & 1627 & 402 & 402 & 398 & 377 \\
\hline 2016 & 3810 & 3811 & - & 806 & 2988 & 2946 & - & 1621 & 417 & 415 & - & 386 \\
\hline 2017 & 3883 & - & 2939 & 823 & 3008 & - & 2611 & 1620 & 436 & - & 421 & 399 \\
\hline 2018 & 3694 & 3647 & - & 802 & 2938 & 2904 & - & 1578 & 484 & 479 & - & 445 \\
\hline \multicolumn{7}{|c|}{ Nota: IV cuarto grado (cuarto básico); VI = sexto grado (cuarto básico); VII = octavo grado (octavo bási- } \\
\hline
\end{tabular}

\section{Instrumento}

Utilizamos el indicador ICE de la Agencia de Calidad de la Educación de Chile, organismo encargado de aplicar, administrar y evaluar esta prueba (Ministerio de Educación de Chile, 2011). Este instrumento corresponde a un cuestionario de autorreporte que se aplica de forma anual en conjunto con la prueba SIMCE. En particular, el ICE se compone de tres dimensiones: ambiente organizado, ambiente de respeto y ambiente seguro. Sin embargo, hasta 2018, en Chile, los resultados de los IDPS son entregados a las escuelas mediante un indicador global que no distingue entre actores ni dimensiones. En el ICE, las percepciones de estudiantes contribuyen en un 50\%, los profesores, en un 10\%, y los apoderados, en un 40\% (Ministerio de Educación de Chile, 2013).

\section{Plan de análisis}

Llevamos a cabo un análisis secundario del ICE. Para ello, solicitamos las bases de datos desagregadas por actor a partir de la Ley de Transparencia (Secretaría General de la Presidencia de Chile, 2008). En primer lugar, realizamos un análisis descriptivo del ICE según año de aplicación por actor y nivel de enseñanza. Luego, para indagar las diferencias aparentes, efectuamos un análisis comparativo de medias a través del análisis de varianza (ANOVA) (Bakieva, González y Jornet, 2012), según el tipo de establecimiento (variable independiente: dependencia administrativa), y utilizamos los valores de F $(p<.05)$. Para constatar las diferencias en el indicador, recurrimos al indicador post hoc Scheffé $(p<.05)$, el cual permite corroborar qué diferencias son estadísticamente significativas (Lee \& Lee, 2018). Los datos fueron examinados por medio del paquete estadístico SPSS versión 23.

\section{Aspectos éticos}

El estudio siguió los principios y consideraciones éticas del comité de bioética y bioseguridad de la Pontificia Universidad Católica de Valparaíso y la Agencia de Calidad de la Educación de Chile. 


\section{RESULTADOS}

\section{Análisis descriptivo}

Los resultados descriptivos muestran, en términos generales, una percepción más positiva del ICE de apoderados. Esto se repite en diferentes niveles de enseñanza y años evaluados, a excepción de la evaluación de cuarto grado de 2017-2018 y sexto grado 2018 (ver tabla 2). Estos resultados ayudan a constatar dos elementos. En primer lugar, que las percepciones del indicador entre los actores pertenecientes a un mismo curso y realidad educativa son distintas y, por otro, que los estudiantes presentan una visión más crítica del clima escolar.

Al analizar el ICE por nivel de enseñanza, observamos, anualmente, una disminución en el puntaje del indicador conforme al nivel evaluado. Los estudiantes y apoderados pertenecientes a un nivel de enseñanza más alto presentan una peor percepción del clima de convivencia escolar. Esto se repite en todos los años evaluados. Lo anterior lo podríamos explicar desde una mayor interiorización de la cultura escolar que favorece una visión más crítica de la convivencia dentro de la escuela.

Otro aspecto importante es que el indicador de décimo grado presenta una menor variabilidad entre sus respuestas (DS entre 4.72 y 7.25 ).

Tabla 2. Estadísticas descriptivas ICE según nivel de enseñanza, actor y año de aplicación

\begin{tabular}{|c|c|c|c|c|c|c|c|c|c|c|}
\hline \multirow{2}{*}{$\begin{array}{c}\text { Nivel de } \\
\text { enseñanza/ } \\
\text { actor }\end{array}$} & \multicolumn{9}{|c|}{ Año aplicación } \\
\cline { 2 - 13 } & \multicolumn{2}{|c|}{2014} & \multicolumn{2}{|c|}{2015} & \multicolumn{2}{c|}{2016} & \multicolumn{2}{c|}{2017} & \multicolumn{2}{c|}{2018} \\
\hline Cuarto grado & M & DS & M & DS & M & DS & M & DS & M & DS \\
\hline Estudiantes & 74,73 & 9,20 & 70,50 & 9,31 & 71,06 & 7,84 & 78,15 & 7,36 & 78,06 & 7,00 \\
\hline Apoderados & 77,16 & 8,96 & 76,03 & 9,22 & 74,82 & 8,96 & 75,34 & 7,61 & 75,76 & 7,77 \\
\hline Sexto grado & & & & & & & & & & \\
\hline Estudiantes & 74,76 & 9,89 & 70,29 & 10,61 & 71,41 & 8,24 & - & - & 77,95 & 6,67 \\
\hline Apoderados & 76,40 & 9,15 & 77,02 & 9,50 & 72,86 & 9,67 & - & - & 74,91 & 7,99 \\
\hline Octavo grado & & & & & & & & & & \\
\hline Estudiantes & 74,76 & 9,89 & 66,70 & 7,47 & - & - & 69,69 & 6,47 & - & - \\
\hline Apoderados & 76,40 & 9,15 & 74,22 & 7,41 & - & - & 73,72 & 6,06 & - & - \\
\hline Décimo grado & & & & & & & & & & \\
\hline Estudiantes & 74,01 & 5,88 & 62,46 & 6,38 & 57,89 & 6,53 & 67,57 & 4,72 & 68,21 & 4,73 \\
\hline Apoderados & 75,01 & 7,25 & 74,21 & 6,72 & 71,69 & 6,93 & 73,51 & 4,94 & 74,10 & 4,86 \\
\hline & & & & & & & & \\
\hline
\end{tabular}

\section{Análisis comparativo}

ICE cuarto grado

El ICE de estudiantes de cuarto grado mostró diferencias significativas según dependencia para todos los años evaluados $(p<.05)$. Estas diferencias muestran una mejor valoración del clima de convivencia escolar en establecimientos particulares, seguidos de los subvencionados y municipales. A pesar de ello, en 2015 hay una percepción levemente superior del ICE de estudiantes de escuelas municipales por sobre particulares subvencionadas. Por otro lado, el ICE de apoderados reporta 
un comportamiento similar que constata una mejor valoración en las privadas. No obstante, al igual que en el caso anterior, en 2018, advertimos una percepción levemente superior en establecimientos municipales por encima de subvencionados (ver tabla 3).

Tabla 3. Comparaciones ICE cuarto grado según dependencia por actor y año de aplicación

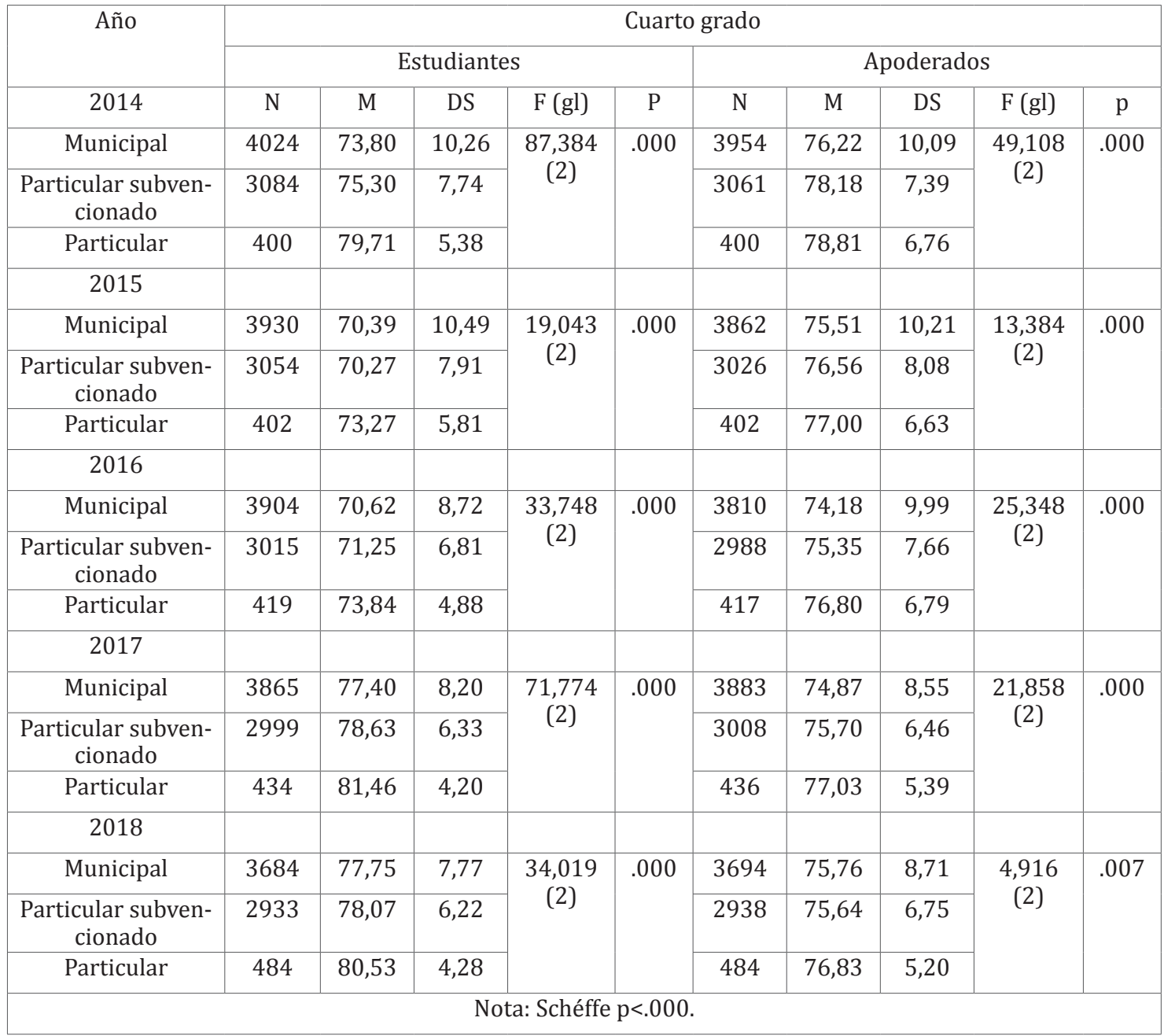

En términos generales, estos resultados nos permiten constatar que, para cuarto grado, las visiones entre apoderados y estudiantes tienden a ser más próximas y mantienen, incluso, una distribución similar entre dependencias.

\section{ICE sexto grado}

El ICE de estudiantes de sexto grado apunta diferencias significativas para todos los años evaluados $(p<.05)$. No obstante, estas demuestran ser variables en función de la cohorte, por lo que constatan una amplia variabilidad entre dependencias. Por su parte, el ICE de apoderados señala diferencias significativas en todos los años evaluados $(p<.05)$, las cuales revelan una mejor percepción de los apoderados pertenecientes a establecimientos privados respecto a los subvencionados y municipales. A pesar de ello, en 2018, observamos una diferencia entre los 
apoderados de establecimientos municipales y particular-subvencionados, lo que confirma una mejor percepción de los primeros sobre los segundos (ver tabla 4).

Tabla 4. Comparaciones ICE sexto grado según dependencia por actor y año de aplicación

\begin{tabular}{|c|c|c|c|c|c|c|c|c|c|c|}
\hline \multirow{3}{*}{$\begin{array}{c}\text { Año } \\
2014\end{array}$} & \multicolumn{10}{|c|}{ Sexto grado } \\
\hline & \multicolumn{5}{|c|}{ Estudiantes } & \multicolumn{5}{|c|}{ Apoderados } \\
\hline & $\mathrm{N}$ & M & DS & $\mathrm{F}(\mathrm{gl})$ & $\mathrm{p}$ & $\mathrm{N}$ & M & DS & $\mathrm{F}(\mathrm{gl})$ & $\mathrm{p}$ \\
\hline Municipal & 4005 & 74,70 & 11,244 & \multirow{3}{*}{$\begin{array}{c}21,849 \\
\text { (2) }\end{array}$} & \multirow{3}{*}{.000} & 3925 & 75,69 & 10,320 & \multirow{3}{*}{$\begin{array}{c}27,219 \\
\text { (2) }\end{array}$} & \multirow{3}{*}{.000} \\
\hline $\begin{array}{l}\text { Particular subven- } \\
\text { cionado }\end{array}$ & 3042 & 74,62 & 8,193 & & & 2997 & 77,13 & 7,585 & & \\
\hline Particular & 396 & 76,35 & 6,435 & & & 393 & 77,96 & 6,622 & & \\
\hline \multicolumn{11}{|l|}{2015} \\
\hline Municipal & 3894 & 70,78 & 12,099 & \multirow{3}{*}{$\begin{array}{c}10,956 \\
\text { (2) }\end{array}$} & \multirow{3}{*}{.000} & 3834 & 76,65 & 10,802 & \multirow{3}{*}{$\begin{array}{c}6,779 \\
(2)\end{array}$} & \multirow{3}{*}{.001} \\
\hline $\begin{array}{l}\text { Particular subven- } \\
\text { cionado }\end{array}$ & 3015 & 69,59 & 8,820 & & & 3001 & 77,36 & 7,909 & & \\
\hline Particular & 402 & 70,74 & 6,433 & & & 402 & 77,96 & 6,407 & & \\
\hline \multicolumn{11}{|l|}{2016} \\
\hline Municipal & 3893 & 71,44 & 9,196 & \multirow{3}{*}{$\begin{array}{l}0,210 \\
(2)\end{array}$} & \multirow{3}{*}{.000} & 3811 & 72,24 & 10,873 & \multirow{3}{*}{$\begin{array}{c}23,919 \\
\text { (2) }\end{array}$} & \multirow{3}{*}{.000} \\
\hline $\begin{array}{l}\text { Particular subven- } \\
\text { cionado }\end{array}$ & 2974 & 71,36 & 7,130 & & & 2946 & 73,34 & 8,188 & & \\
\hline Particular & 415 & 71,61 & 5,937 & & & 415 & 75,22 & 6,692 & & \\
\hline \multicolumn{11}{|l|}{2018} \\
\hline Municipal & 3636 & 78,47 & 7,476 & \multirow{3}{*}{$\begin{array}{c}25,911 \\
\text { (2) }\end{array}$} & \multirow{3}{*}{.000} & 3647 & 75,08 & 9,046 & \multirow{3}{*}{$\begin{array}{c}5,772 \\
(2)\end{array}$} & \multirow{3}{*}{.003} \\
\hline $\begin{array}{l}\text { Particular subven- } \\
\text { cionado }\end{array}$ & 2899 & 77,52 & 5,686 & & & 2904 & 74,60 & 6,798 & & \\
\hline Particular & 478 & 76,69 & 4,841 & & & 479 & 75,77 & 5,359 & & \\
\hline & & & & & $<.0$ & & & & & \\
\hline
\end{tabular}

En general, en sexto grado, las percepciones entre estudiantes y apoderados tienden a diferenciarse y registran variables en función del año y la dependencia en la que se evalúa el indicador. No obstante, los apoderados parecen tener una visión similar a la de cuarto grado, esto es, una mejor valoración del clima de establecimientos privados.

\section{ICE octavo grado}

Respecto al ICE de estudiantes de octavo grado, solo se muestran diferencias significativas para $2017(p=.000)$. Estos resultados reflejan una mejor percepción del clima de convivencia escolar en establecimientos municipalizados en relación con subvencionados y particulares. Por otro lado, el ICE de apoderados presenta diferencias significativas para todos los años $(p=.000)$, lo que confirma una mejor percepción en establecimientos privados por sobre subvencionados y municipales (ver tabla 5). 
Tabla 5. Comparaciones ICE octavo grado según dependencia por actor y año de aplicación

\begin{tabular}{|c|c|c|c|c|c|c|c|c|c|c|}
\hline \multirow{3}{*}{$\begin{array}{c}\text { Año } \\
2014\end{array}$} & \multicolumn{10}{|c|}{ Octavo grado } \\
\hline & \multicolumn{5}{|c|}{ Estudiantes } & \multicolumn{5}{|c|}{ Apoderados } \\
\hline & $\mathrm{N}$ & M & DS & $\mathrm{F}(\mathrm{gl})$ & $\mathrm{p}$ & $\mathrm{N}$ & M & DS & $\mathrm{F}(\mathrm{gl})$ & $\mathrm{p}$ \\
\hline Municipal & 2847 & 74,10 & 6,209 & \multirow{3}{*}{$\begin{array}{c}0,653 \\
(2)\end{array}$} & \multirow{3}{*}{.520} & 2840 & 73,47 & 7,423 & \multirow{3}{*}{$\begin{array}{c}134,336 \\
(2)\end{array}$} & \multirow{3}{*}{.000} \\
\hline $\begin{array}{l}\text { Particular sub- } \\
\text { vencionado }\end{array}$ & 2638 & 73,93 & 5,602 & & & 2621 & 76,30 & 6,854 & & \\
\hline Particular & 400 & 73,90 & 5,261 & & & 399 & 77,45 & 6,160 & & \\
\hline \multicolumn{11}{|l|}{2015} \\
\hline Municipal & 2914 & 66,80 & 8,048 & \multirow{3}{*}{$\begin{array}{c}0,511 \\
(2)\end{array}$} & \multirow{3}{*}{.600} & 2909 & 72,83 & 7,685 & \multirow{3}{*}{111,153} & \multirow{3}{*}{.000} \\
\hline $\begin{array}{l}\text { Particular sub- } \\
\text { vencionado }\end{array}$ & 2625 & 66,60 & 6,919 & & & 2621 & 75,38 & 6,921 & & \\
\hline Particular & 398 & 66,73 & 6,575 & & & 398 & 76,78 & 6,319 & & \\
\hline \multicolumn{11}{|l|}{2017} \\
\hline Municipal & 2939 & 70,50 & 6,775 & \multirow{3}{*}{$\begin{array}{c}48,155 \\
(2)\end{array}$} & \multirow{3}{*}{.000} & 2939 & 72,73 & 6,283 & \multirow{3}{*}{90,606} & \multirow{3}{*}{.000} \\
\hline $\begin{array}{l}\text { Particular sub- } \\
\text { vencionado }\end{array}$ & 2611 & 69,03 & 6,178 & & & 2611 & 74,46 & 5,758 & & \\
\hline Particular & 421 & 68,24 & 5,254 & & & 421 & 75,99 & 4,985 & & \\
\hline \multicolumn{11}{|c|}{ Nota: Schéffe $\mathrm{p}<.000$. } \\
\hline
\end{tabular}

Los resultados de octavo grado dan cuenta de una mayor variabilidad en el indicador de estudiantes, los cuales, además, presentan márgenes estrechos entre dependencias. En el caso de los apoderados, el indicador obtiene una distribución similar a los otros niveles evaluados.

\section{ICE décimo grado}

El ICE de estudiantes de décimo grado (segundo medio) revela diferencias significativas para todos los años evaluados $(p<.05)$. Estas diferencias evidencian una mejor percepción del clima en establecimientos privados si los comparamos con los subvencionados y municipales. Por su parte, el ICE de apoderados tiene resultados similares, que constatan una mejor percepción en establecimientos privados $(p=.000)$ (ver tabla 6).

Tabla 6. Comparaciones ICE décimo grado según dependencia por actor y año de aplicación

\begin{tabular}{|c|c|c|c|c|c|c|c|c|c|c|}
\hline \multirow{3}{*}{$\begin{array}{c}\text { Año } \\
2014\end{array}$} & \multicolumn{10}{|c|}{ Décimo grado } \\
\hline & \multicolumn{5}{|c|}{ Estudiantes } & \multicolumn{5}{|c|}{ Apoderados } \\
\hline & $\mathrm{N}$ & $\mathrm{M}$ & DS & $\mathrm{F}(\mathrm{gl})$ & $\mathrm{p}$ & $\mathrm{N}$ & M & DS & $\mathrm{F}(\mathrm{gl})$ & $\mathrm{p}$ \\
\hline Municipal & 678 & 70,23 & 4,538 & \multirow{3}{*}{87,939 (2) } & \multirow{3}{*}{.000} & 676 & 71,41 & 6,006 & \multirow{3}{*}{$\begin{array}{c}203,193 \\
(2)\end{array}$} & \multirow{3}{*}{.000} \\
\hline $\begin{array}{l}\text { Particular sub- } \\
\text { vencionado }\end{array}$ & 1621 & 72,49 & 4,752 & & & 1617 & 76,50 & 6,290 & & \\
\hline Particular & 372 & 73,96 & 4,857 & & & 372 & 78,11 & 5,892 & & \\
\hline \multicolumn{11}{|l|}{2015} \\
\hline Municipal & 785 & 59,78 & 5,804 & \multirow{3}{*}{$\begin{array}{c}140,039 \\
(2)\end{array}$} & \multirow{3}{*}{.000} & 785 & 70,12 & 6,130 & \multirow{3}{*}{$\begin{array}{c}250,842 \\
(2)\end{array}$} & \multirow{3}{*}{.000} \\
\hline $\begin{array}{l}\text { Particular sub- } \\
\text { vencionado }\end{array}$ & 1630 & 62,97 & 6,161 & & & 1627 & 75,39 & 6,358 & & \\
\hline Particular & 377 & 65,90 & 6,645 & & & 377 & 77,50 & 5,904 & & \\
\hline
\end{tabular}




\begin{tabular}{|c|c|c|c|c|c|c|c|c|c|c|}
\hline 2016 & & & & & & & & & & \\
\hline Municipal & 806 & 55,63 & 6,188 & \multirow{3}{*}{$84,733(2)$} & \multirow{3}{*}{.000} & 806 & 67,63 & 6,154 & \multirow{3}{*}{$\begin{array}{c}255,937 \\
\text { (2) }\end{array}$} & \multirow{3}{*}{.000} \\
\hline $\begin{array}{l}\text { Particular sub- } \\
\text { vencionado }\end{array}$ & 1628 & 58,48 & 6,416 & & & 1621 & 72,78 & 6,564 & & \\
\hline Particular & 387 & 60,29 & 6,630 & & & 386 & 75,56 & 6,235 & & \\
\hline \multicolumn{11}{|l|}{2017} \\
\hline Municipal & 823 & 66,73 & 4,491 & \multirow{3}{*}{$22,171(2)$} & \multirow{3}{*}{.000} & 823 & 70,61 & 4,410 & \multirow{3}{*}{$\begin{array}{c}268,078 \\
\text { (2) }\end{array}$} & \multirow{3}{*}{.000} \\
\hline $\begin{array}{l}\text { Particular sub- } \\
\text { vencionado }\end{array}$ & 1618 & 67,81 & 4,736 & & & 1620 & 74,32 & 4,630 & & \\
\hline Particular & 399 & 68,45 & 5,013 & & & 399 & 76,33 & 4,561 & & \\
\hline \multicolumn{11}{|l|}{2018} \\
\hline Municipal & 802 & 67,72 & 4,393 & \multirow{3}{*}{$6,598(2)$} & \multirow{3}{*}{.001} & 802 & 72,11 & 4,455 & \multirow{3}{*}{$\begin{array}{c}126,146 \\
(2)\end{array}$} & \multirow{3}{*}{.000} \\
\hline $\begin{array}{l}\text { Particular sub- } \\
\text { vencionado }\end{array}$ & 1578 & 68,28 & 4,781 & & & 1578 & 74,52 & 4,786 & & \\
\hline Particular & 444 & 68,67 & 5,160 & & & 445 & 76,26 & 4,730 & & \\
\hline
\end{tabular}

Los resultados de décimo grado observan percepciones más próximas entre apoderados y estudiantes, las cuales tienden a ser más críticas desde la dependencia municipal. Estas percepciones podrían estar influidas por el tiempo dentro de la escuela, lo que favorece una mayor interiorización de la cultura escolar y, por ende, una visión más crítica de esta.

\section{ConCLUSión}

La medición de la calidad educativa debe ser entendida bajo un modelo multidimensional que integre la complejidad de las escuelas y permita su abordaje en cuanto a comunidad escolar y política pública. Las escuelas no solo deben proporcionar contenidos de aprendizaje a sus estudiantes, sino también propiciar espacios de desarrollo que posibiliten una experiencia escolar positiva a fin de que adquieran habilidades y valores que favorezcan la vida en sociedad. La preocupación por la convivencia escolar resulta crucial, pues permite beneficiar u obstaculizar el desarrollo de estas habilidades (Maxwell et al., 2017; López et al., 2011; Barca et al., 2012).

A pesar de los avances en las mediciones de calidad en Chile (sobre todo la incorporación de dimensiones no académicas), algunos autores (Assael et al., 2011; Herrera, Reyes-Jedlicki y Ruiz, 2018; Anaya, 2019) han demostrado un vínculo entre estas mediciones y la preservación de un mercado educativo. Estas interpretaciones se sustentan en una valoración y medición que favorece lo privado por encima de lo público.

En este contexto, nuestro estudio se propuso un doble objetivo: analizar las percepciones de estudiantes y apoderados respecto al ICE para las cohortes 2014-2018, y comparar las diferencias en el ICE según el tipo de escuela (dependencia administrativa) a la que pertenecen.

Respecto al primer objetivo, los resultados indican diferencias entre las percepciones de apoderados y estudiantes, lo que constata una mejor valoración del clima de convivencia escolar por parte de apoderados. Estos resultados son coherentes con investigaciones nacionales respecto al indicador (Padilla y Rodríguez, 2019; Ascorra et al., 2020b) y con investigaciones internacionales (Deemer, 2004; Johnson, Stevens \& Zvoch, 
2007; Torres-Vallejos, 2020). De esta manera, a pesar de que estudiantes, docentes y apoderados compartan, dentro de una misma escuela, sus percepciones, pueden diferir en función de sus experiencias, significados y roles (Padilla y Rodríguez, 2019).

Estos hallazgos llevan a cuestionar la actual forma en que se comprende, mide y entregan los resultados del ICE en Chile. En primer lugar, un estudio desarrollado por Ascorra y colegas (2020b) ha discutido la definición del indicador como "clima de convivencia escolar", pues responde a tradiciones de pensamiento distintas. El clima escolar obedece a aspectos académicos, de seguridad y medio ambiente institucional (Wang \& Degol, 2015), lo que, según Galtung (2013), se define como una perspectiva estrecha. Por su parte, la convivencia escolar se preocupa por la resolución y restauración de los conflictos escolares de manera pacífica e inclusiva, lo cual se reconoce como una perspectiva amplia.

En segundo lugar, el indicador entregado a las escuelas (al menos hasta 2018) no distingue entre actores y dimensiones de análisis, lo que dificulta su comprensión. Respecto a ello, estudios previos han visualizado que las dimensiones del ICE (ambiente de respeto, organizado y seguro) comprenden la convivencia escolar desde una perspectiva estrecha, al evaluar ante todo el rol que cumple la escuela en la mantención de la paz (Ascorra et al., 2020b, 2018). De acuerdo con la revisión teórica, estas dimensiones son muy valoradas por los apoderados de NSE bajo y medio (Córdoba, Laborda y Reyes, 2020; Bellei et al., 2016; Canales, Bellei y Orellana, 2016), y son aspectos para considerar al momento de elegir una escuela. De esta manera, el ICE de apoderados respondería de forma acertada a los intereses del mercado educativo, y respaldaría la hipótesis de un sistema de evaluación que distingue previamente entre establecimientos públicos y privados.

Por otro lado, el ICE, desde una perspectiva agregada multiactor, entrega una alta ponderación a apoderados (40\%) e instala un indicador único que distorsiona la medición de la convivencia escolar. Proponemos como hipótesis que esta mayor contribución de la percepción de apoderados responde a la conservación del mercado educativo, pues otorga mayor relevancia a estos actores por sobre los docentes, quienes se involucran de modo directo en la gestión del clima y convivencia escolar. Adhiriéndonos a una perspectiva crítica, las políticas e indicadores no son neutros, sino que contribuyen a la subsistencia de determinados fines; en este caso, al valor que se le da a la elección de escuela por parte de los apoderados y, con ello, al mercado educativo (Ball, 2003; Anaya, 2019).

En cuanto al segundo objetivo, los resultados del ICE de apoderados permitieron constatar diferencias significativas entre dependencias para todos los niveles y cohortes. Estas diferencias mostraron tener una distribución similar y corroboraron una mejor valoración de la convivencia en establecimientos privados. Asimismo, confirmamos una peor valoración en establecimientos municipales para todos los niveles y cohortes, a excepción del indicador de cuarto grado de 2014 y de sexto grado de 2018, aunque con márgenes bastante estrechos, por lo que no pudimos atribuir una explicación causal.

Estos hallazgos en apoderados pueden ser interpretados a partir de los estudios de elección de escuela (school choice), los cuales han expuesto elementos socioculturales que podrían explicar estas diferencias. En primer lugar, en todos los niveles 
socioeconómicos, las escuelas privadas son mejor valoradas, y se les atribuye una calidad de la educación más alta, una experiencia escolar óptima y mejores relaciones interpersonales (Canales, Guajardo y Orellana, 2020; Córdoba, Laborda y Reyes, 2020). En cambio, las municipales son percibidas por los apoderados como de menor calidad, inseguras y con altos niveles de violencia (Córdoba, Laborda y Reyes, 2020; Canales, Bellei y Orellana, 2016).

De esta manera, incluso antes de ingresar a una escuela, se atribuyen condiciones negativas o positivas en función del estrato socioeconómico que participa en ella. En consecuencia, los apoderados tendrían una peor valoración de lo público en diferentes aspectos, lo cual puede interferir en la interpretación del clima y la convivencia escolar.

Como hipótesis, consideramos que estas nociones se han mantenido y reforzado a través de las evaluaciones de calidad, las cuales, reiteradamente y en distintos aspectos, posicionan mejor a la escuela privada que a la pública. En este contexto y tomando en cuenta la existencia de un mercado educativo y libre elección, en el cual los apoderados juegan un papel fundamental en el desarrollo de la "oferta educativa", no nos parecen azarosas las estrategias de medición de calidad desplegadas por la política pública. Hallazgos similares han sido reportados en América Latina al señalar que "discursos mediáticos y de sentido común han construido una fuerte asociación simbólica entre escuelas de élite, educación de gestión privada y calidad educativa, supuesto que la investigación científica ha comenzado a problematizar" (Ziegler, Gessaghi y Fuentes, 2018, p. 41).

Asimismo, si un apoderado está dispuesto a pagar altas sumas de dinero por la educación de sus hijos (escuelas privadas) o aportar con copago (escuelas subvencionadas), lo más probable es que mantendría una valoración positiva de la escuela, ya que, de otro modo, no incurriría en ese gasto. En cambio, los apoderados de NSE bajo cuentan con escasas posibilidades de elección, lo cual podría propiciar una evaluación más crítica de sus escuelas.

Por otro lado, las escuelas municipales presentan una matrícula escolar más diversa y desafiante. La mayoría de estas se conforman de estudiantes con trayectorias educacionales diversas, bajo nivel socioeconómico, necesidades educativas, migrantes, entre otros aspectos, grupos altamente discriminados y marginalizados. Suponemos que estos elementos pueden volver más compleja la evaluación de los indicadores de calidad en apoderados.

Respecto a los resultados del ICE de estudiantes, estos mostraron tener una distribución más inestable y sensible a la cohorte y año de aplicación. En este sentido, las percepciones de estudiantes parecen ser más críticas que las de sus apoderados, y responden de manera más clara a elementos propios del clima y convivencia escolar. Estudios previos habían constatado que aspectos como las relaciones interpersonales positivas, ser tratado justamente, tener la posibilidad de opinar e incidir en temas relevantes para la escuela son considerados como importantes por los estudiantes (Cavieres, 2014; López et al., 2013).

De este modo, sus percepciones podrían diferir de las de sus apoderados en función de su propia experiencia escolar, y dejar en segundo plano aspectos como el tipo de escuela a la que se asiste. Llama la atención en este estudio las percepciones de estudiantes de sexto grado en 2015 y 2018, y las de estudiantes de octavo grado 
en 2017, las cuales dan cuenta de una mejor valoración del ICE en establecimientos municipales respecto a los subvencionados y privados. Esta situación nos plantea la relevancia de visualizar y contrastar las percepciones entre actores.

En general, estos hallazgos ponen en relieve la escasa comunicación positiva que reciben las escuelas municipales, a las cuales se les atribuyen resultados negativos; esto no se condice con los hallazgos en estudiantes, sino que se vuelve relevante, pues, como hipótesis, señalamos que el foco por la calidad educativa concede espacio a la mantención de un mercado de educación que requiere sostener en el imaginario social del país la debilidad que presenta la educación pública. Así, indicadores que agregan percepciones de apoderados, estudiantes y profesores, sí logran apoyar con evidencia el imaginario social, lo que no ocurre si atendemos únicamente las percepciones de estudiantes. Sumado a lo anterior, es posible sostener que, para determinadas cohortes y años, la educación privada presenta peores resultados en el ICE, lo que contraviene los principios de libertad de mercado ya enunciados.

Estos hallazgos, además, "plantean una dificultad para la política pública, esto es, que dejan en un segundo plano la preocupación por construir comunidades escolares que propendan a la conservación de una paz duradera" (Fierro, 2013, p. 24). En este sentido, la política no solo debiese avanzar en valorar las percepciones entre actores de manera desagregada -resguardando un diagnóstico acabado de las comunidades escolares-, sino que también debiese replantearse el contenido de estas evaluaciones. Consideramos que integrar a la medición del ICE una perspectiva amplia de la convivencia escolar que comprenda elementos como el reconocimiento de las diferencias, la participación en las decisiones de la escuela, la existencia de mecanismos dialógicos y deliberativos, el vínculo con el territorio, entre otros aspectos, puede ser significativo.

Sería relevante que futuras investigaciones pudieran constatar otras mediciones del clima o convivencia escolar con el objetivo de realizar comparaciones entre indicadores que permitan nutrir su medición y comprensión. Como señalamos, las mediciones de calidad educativa deben incorporar una visión multidimensional que permita a las escuelas poder informarse de manera adecuada y oportuna (Santos y Elacqua, 2016). Contar con mediciones robustas favorece que las escuelas identifiquen dimensiones específicas de mejora y desarrollo, y les ayude a avanzar hacia una gestión certera.

Asimismo, nos parece importante que futuras investigaciones puedan profundizar cualitativamente en las percepciones de apoderados de establecimientos privados. Esto, porque la literatura respecto a este actor es más bien escasa, y es en esta institución donde políticas como las de convivencia escolar no son exigidas de la misma manera entre dependencias. En concreto, en temas como la conformación de un consejo escolar -organismo multiestamental-, las escuelas privadas no tienen la obligatoriedad de cumplir con este requerimiento, lo que sí se plantea para escuelas con financiamiento del estado (municipales y subvencionadas). Así, podemos visualizar un funcionamiento de estos establecimientos al margen de las políticas, lo que podría contribuir a una construcción de escuelas "intocables", subjetividad que ha sido reportada a nivel internacional en escuelas privadas (Barrera, Falabella y Ilabaca, 2021). 
De igual manera, consideramos necesario que futuras investigaciones puedan indagar cualitativamente las percepciones de distintos actores de la comunidad escolar. A pesar de que existen estudios previos que refieren diferencias a nivel sociocultural en los apoderados, y que estos estudios han referido dimensiones del clima y convivencia escolar, su objetivo ha sido abordar los criterios o factores que inciden en la elección de escuela, no así el análisis de las percepciones del clima o la convivencia escolar. Nos parece necesario comprender el contexto donde se dan estas diferencias entre apoderados de distintas dependencias.

Finalmente, planteamos como limitación de este estudio las posibilidades de analizar las percepciones de profesores respecto al ICE. Dadas las diferencias entre los distintos actores respecto a la convivencia escolar, resulta primordial conocer cómo se valora y comprende este fenómeno por parte de los profesores, sobre todo por su relevancia en la gestión del clima y la convivencia escolar.

\section{REFERENCIAS BIBLIOGRÁFICAS}

Agencia de Calidad de la Educación (2019). Informe Técnico Categorías de Desempeño. http://archivos.agenciaeducacion.cl/Informe_Tecnico_CD.pdf

Agencia de Calidad de la Educación (2018). Indicadores de desarrollo personal y social (IDPS) medidos a través de cuestionarios. Informe técnico 2017. https:// bibliotecadigital.mineduc.cl/bitstream/handle/20.500.12365/4572/ IDPS_2017.pdf?sequence $=1 \&$ isAllowed $=y$

Anaya, E. (2019). Calidad educativa como precarización laboral: análisis de América Latina. Revista Latinoamericana de Estudios Educativos, vol. 49, núm. 2, pp. 9-34. https://doi.org/10.48102/rlee.2019.49.2.15

Ascorra, P., Cárdenas, K. y Álvarez-Figueroa, F. (2020). Gestión de la convivencia escolar a nivel intermedio: diseño y validación de una escala. Revista Evaluar, vol. 20, núm. 3, pp. 1-19. https://doi.org/10.35670/1667-4545.v20. n3.31700

Ascorra, P., Cárdenas, K., Gálvez, P., Ávila, A. y González, C. (2020a). Relación entre estilos de convivencia e indicadores de desarrollo personal y social en escuelas chilenas. Centro de Investigación para la Educación Inclusiva, Pontificia Universidad Católica de Valparaíso.

Ascorra, P., López, V., Carrasco, C. y Bilbao, M. (2020b). ¿Qué informan los índices multiactor sobre convivencia escolar en Chile?: un análisis de diseño mixto. Centro de Investigación para la Educación Inclusiva. Pontificia Universidad Católica de Valparaíso.

Ascorra, P., Carrasco, C., López, V. y Morales, M. (2019). Políticas de convivencia escolar en tiempos de rendición de cuentas. Archivos Analíticos de Políticas Educativas, vol. 27, núm. 31, pp. 1-27. http://dx.doi.org/10.14507/ epaa.27.3526

Ascorra, P., López, V., Carrasco, C., Pizarro, I., Cuadros, O. y Núñez, C. (2018). Significados atribuidos a la convivencia escolar por equipos directivos, docentes y otros profesionales de escuelas chilenas. Psykhe, vol. 27, núm. 1, pp. 1-12. http://dx.doi.org/10.7764/psykhe.27.1.1214

Assael, J., Cornejo, R., González, J., Redondo, J., Sánchez, R. y Sobarzo, M. (2011). La empresa educativa chilena. Educ. Soc., Campinas, vol. 32, núm. 115, pp. 305-322. https://doi.org/10.1590/S0101-73302011000200004 
Bakieva, M., González Such, J. y Jornet, J. (2012). SPSS: ANOVA de un factor. InnovaMIDE. Universitat de Valéncia. https://www.uv.es/innovamide/spss/ SPSS/SPSS_0702b.pdf

Ball, S. J. (2003). Class strategies and the education market: The middle classes and social advantage. Routledge Falmer.

Barca, A., Almeida, L., Porto, A., Peralbo, M. y Brenlla, J. (2012). Motivación escolar y rendimiento: impacto de metas académicas, de estrategias de aprendizaje y autoeficacia. Anales de Psicología, vol. 8, núm. 3, pp. 848-859. http:// hdl.handle.net/2183/16884

Barrera, J., Falabella, A. y Ilabaca, T. (2021). "Los intocables": la educación escolar de las élites, sus privilegios y nuevos escenarios. Pensamiento Educativo, vol. 58, núm. 1, pp. 1-17. https://dx.doi.org/10.7764/pel.58.1.2021.3

Bellei, C. (2013). El estudio de la segregación socioeconómica y académica de la educación chilena. Estudios pedagógicos (Valdivia), vol. 39, núm. 1, pp. 325345. http://dx.doi.org/10.4067/S0718-07052013000100019

Bellei, C., Canales, M., Orellana, V. y Contreras, M. (2016). Elección de escuela en sectores populares: Estado, mercado e integración social. Revista Austral de Ciencias Sociales, núm. 31, pp. 91-110. https://doi.org/10.4206/rev.austral. cienc.soc.2016.n31-06

Bellei, C. \& Vanni, X. (2015). The evolution of educational policy in Chile, 19802014. En S. Schwartzman (ed.). Education in South America (pp. 179-200). Nueva York, NY: Bloomsbury.

Berger, C., Milicic, N., Alcalay, L., Torretti, A., Arab, M. y Justiniano, B. (2009). Bienestar socio-emocional en contextos escolares. Estudios sobre Educación, vol. 17, pp. 21-43. https://doi.org/10.15581/004.17.21-43

Canales, M., Bellei, C. y Orellana, V. (2016). ¿Por qué elegir una escuela privada subvencionada? Sectores medios emergentes y elección de escuela en un sistema de mercado. Estudios Pedagógicos, vol. XLII, núm. 3, pp. 89-109. http:// dx.doi.org/10.4067/S0718-07052016000400005

Canales, M., Guajardo, F. y Orellana, V. (2020). La elite del llano: de la promesa a las dsilusiones en la trayectoria postsecundaria de los jóvenes de la nueva clase media. Última Década, vol. 53, pp. 78-102. http://dx.doi.org/10.4067/ S0718-22362020000100078

Cárdenas, K. y López, V. (2021). Apoyos psicosociales en escuelas chilenas: entre la vulnerabilidad escolar y la inestabilidad laboral. Manuscrito presentado para publicación. Chile: Centro de Investigación para la Educación Inclusiva, Pontificia Universidad Católica de Valparaíso.

Carrasco, A., Donoso, A. y Mendoza, M. (2016). La dimensión ético-política de la elección de escuela: dilemas en familias chilenas de elite. En J. Corvalán, A. Carrasco y J. García-Huidobro (eds.). Mercado escolar y oportunidad educacional. Libertad, diversidad y desigualdad (pp. 301-335). CEPPE, Ediciones UC. https://doi.org/10.1163/9789463002622_001

Carrasco, A., Falabella, A. \& Mendoza, M. (2015). School choice in Chile as a sociocultural practice. En P. Seppänen et al. (eds.). Contrasting dynamics in education politics of extremes (pp. 245-266). Roterdam: Sense Publishers.

Cavieres, E. (2014). La calidad de la educación como parte del problema: educación escolar y desigualdad en Chile. Revista Brasileira de Educação, vol. 19, núm. 59, pp. 1033-1051. http://dx.doi.org/10.1590/S141324782014000900011 
Cohen, J. \& Geier, V. K. (2010). School climate research summary: January 2010. School Climate Brief, vol. 1, núm. 1, pp. 1-6. https://doi.org/ 10.3102/0034654313483907

Córdoba, C., Laborda, A. y Reyes, C. (2020). Preferencias de elección de escuela en dos casos de alta segregación escolar. REICE. Revista Iberoamericana sobre Calidad, Eficacia y Cambio en Educación, vol. 18, núm. 4, pp. 325-344. https:// doi.org/10.15366/reice2020.18.4.013

Cornejo, R. (2006). El trabajo docente en la institución escolar. La apropiaciónenajenación del proceso de trabajo docente en el contexto de las reformas educativas neoliberales. Revista de psicología, vol. 15, núm. 2, pp. 9-24. DOI: 10.5354/0719-0581.2006.18390

Cornejo, R. y Redondo, J. (2007). Variables y factores asociados al aprendizaje escolar. Una discusión desde la investigación actual. Estudios Pedagógicos, vol. 33, núm. 2, pp. 155-175. http://dx.doi.org/10.4067/S071807052007000200009

Deemer, S. (2004). Classroom goal orientation in high school classrooms: Revealing links between teacher beliefs and classroom environments. Educational Research, vol. 46, pp. 73-90. https://doi.org/10.1080/0013188042000178836

Devine, J. \& Cohen, J. (2007). Making our school safe: Strategies to protect children and promote learning. Teachers College Press.

Escobar, R. (2018). Escuela y democracia. Experiencias en formación ciudadana en establecimientos educacionales de la región metropolitana. Revista Saberes Educativos, núm. 2, pp. 57-75. https://doi.org/10.5354/24525014.2019.52054

Fierro, C. (2013). Convivencia inclusiva y democrática. Una perspectiva para gestionar la seguridad escolar. Sinéctica, Revista Electrónica de Educación, núm. 40, pp. 1-18. http://www.sinectica.iteso.mx/articulo/?id=40_convivencia_inclusiva_y_ democratica_una_perspectiva_para_gestionar_la_seguridad_escolar

Fuentes, C. y Valdeavellano, R. (dir.) (2015). Chicago Boys [documental]. La Ventana Cine.

Galtung, J. (2013). Conflict transformation by peaceful means (The Transcend Method). En J. Galtung \& D. Fischer. Johan Galtung, pioneer of peace research (pp. 59-70). Heidelberg: Springer.

Gayo, M., G. Otero, G. y Méndez, M. L. (2019). Elección escolar y selección de familias: reproducción de la clase media alta en Santiago de Chile. Revista Internacional de Sociología, vol. 77, núm. 120, pp. 1-16. https://doi.org/10.3989/ ris.2019.77.1.17.310

González, R. (2017). Segregación educativa en el sistema chileno desde una perspectiva comparada. En MINECUC (ed.). El primer gran debate de la reforma educacional: Ley de Inclusión Escolar (pp. 48-91). Ministerio de Educación de Chile.

Gubbins, V. (2014). Estrategias educativas de familias de clase alta. Un estudio exploratorio. Revista Mexicana de Investigación Educativa, vol. 19, núm. 63, pp. 1069-1089.

Hernández, R., Fernández, C. y Baptista, P. (2010). Metodología de la Investigación. McGraw-Hill.

Herrera, J. F., Reyes-Jedlicki, L. y Ruiz, C. M. (2018). Escuelas gobernadas por resultados: efectividad escolar y políticas educacionales de la transición democrática, Chile 1990-2017. Psicoperspectivas, vol. 17, núm. 2, pp.1-12. https:// doi.org/10.5027/psicoperspectivas-vol17-issue2-fulltext-1110 
Johnson, B., Stevens, J. J. \& Zvoch, K. (2007). Teachers' perceptions of school climate: A validity study of scores from the Revised School Level Environment Questionnaire. Educational and Psychological Measurement, vol. 67, núm. 5, pp. 833-844. https://doi.org/10.1177/0013164406299102

Lee, S. \& Lee, D. K. (2018). What is the proper way to apply the multiple comparison test? Korean Journal of Anesthesiology, vol. 71, núm. 5, pp. 353-360. https://doi.org/10.4097/kja.d.18.00242

López, V., Ascorra, P., Bilbao, M., Carrasco, C., Morales, M., Villalobos B. y Ayala, A. (2013). Monitorear la convivencia escolar para fortalecer (no disminuir) las capacidades de las escuelas. Revista Iberoamericana de Evaluación Educativa, vol. 6, núm. 2, pp. 201-219. https://revistas.uam.es/riee/ article/view/3413

López, V., Carrasco, C., Morales, M., Ayala, Á., López, J. y Karmy, M. (2011). Individualizando la violencia escolar: análisis de prácticas discursivas en una escuela municipal de la región de Valparaíso. Psykhe, vol. 20, núm. 2, pp. 7-23. http://dx.doi.org/10.4067/S0718-22282011000200002

Maxwell, S., Reynolds, K. J., Lee, E., Subasic, E. \& Bromhead, D. (2017). The impact of school climate and school identification on academic achievement: Multilevel modeling with student and teacher data. Front. Psychol, vol. 8, pp. 1-21. https://doi.org/10.3389/fpsyg.2017.02069

Ministerio de Educación de Chile (2019). Orientaciones para la elaboración del Plan de Mejoramiento Educativo. División de Educación General.

Ministerio de Educación de Chile (2013). Decreto No. 381. Establece los otros indicadores de calidad educativa a que se refiere el artículo $3^{\circ}$, letra a), de la ley $\mathrm{n}$ - 20.529, que establece el sistema nacional de aseguramiento de la calidad de la educación parvularia, básica y media y su fiscalización (10 de julio). Biblioteca del Congreso Nacional de Chile. https://www.leychile.cl/ $\mathrm{N} ? \mathrm{i}=1055510 \& \mathrm{f}=2013-10-25 \& \mathrm{p}=$

Ministerio de Educación de Chile (2011). Ley No. 20.529. Sobre el Sistema Nacional de Aseguramiento de la Calidad de la Educación Escolar (Ley SAC, 11 de agosto). Biblioteca del Congreso Nacional de Chile._http://bcn.cl/1uv5c

Ministerio de Educación de Chile (1990). Ley No. 18.962. Ley Orgánica Constitucional de Enseñanza (7 de marzo). Biblioteca del Congreso Nacional de Chile. http://bcn.cl/2k1tr

National School Climate Center (2012). School Climate Research Summary: August 2012. https://www.schoolclimate.org/storage/app/media/PDF/scbrief-v3.pdf

OCDE (2016). Global competency for an inclusive world. París, Francia. https:// bit.ly/2kHxsLu

Orellana, V., Caviedes, S., Bellei, C. y Contreras, M. (2018). La elección de escuela como fenómeno sociológico. Una revisión de literatura. Revista Brasileira de Educação, vol. 23, núm. 230007, pp. 1-19. http://dx.doi.org/10.1590/S141324782018230007

Padilla, G. y Rodríguez, C. (2019). Clima de convivencia escolar en Chile: un análisis desde el nuevo marco de medición de calidad educativa. Revista Educación, vol. 43, núm. 2, pp. 1-16. https://doi.org/10.15517/revedu.v43i2.34117

Prieto, M. (2019). Percepciones del profesorado sobre las políticas de aseguramiento de la calidad educativa en Chile. Educ. Soc., Campinas, vol. 40, pp. 1-20. http://dx.doi.org/10.1590/es0101-73302019189573 
Raczynski, D. y Muñoz, G. (2004). Factores que desafían los buenos resultados educativos de escuelas en sectores de pobreza. Fondo de Investigaciones Educativas-Programa de Promoción de la Reforma Educativa en América Latina y el Caribe. https://bibliotecadigital.mineduc.cl/bitstream/handle/20.500.12365/2110/mono-926.pdf?sequence=1\&isAllowed=y

Rivers, I., Poteat, V. P., Noret, N. \& Ashurst, N. (2009). Observing bullying at school: The mental health implications of witness status. School Psychology Quarterly, vol. 24, núm. 4, pp. 211-223. https://doi.org/10.1037/a0018164

Rodríguez-Garcés, C., Padilla-Fuentes, G. y Suazo, C. (2020). Medición de calidad educativa en Chile: lo que reportan los indicadores de desarrollo cognitivo, personal y social en la escuela. Revista Pilquen, vol. 17, núm. 1, pp. 34-48. http://revele.uncoma.edu.ar/htdoc/revele/index.php/psico/article/ view $/ 2647$

Rodríguez, R. (1996). Teoría básica del muestreo. Buenos Aires.

Sanhueza, G. (2019). Estado y mercado en la educación. Una discusión en perspectiva histórica de la política educativa chilena: 1980-2018. Diagrama.

Santos, H. y Elacqua, G. (2016). Segregación socioeconómica escolar en Chile: elección de la escuela por los padres y un análisis contrafactual teórico. $R e$ vista CEPAL, vol. 119, pp. 133-148. https://repositorio.cepal.org/bitstream/ handle/11362/40396/1/RVE119_Santos.pdf

Secretaría General de la Presidencia de Chile (2008). Ley No. 20.285. Sobre Acceso a la Información Pública (20 de agosto). Biblioteca del Congreso Nacional de Chile. http://bcn.cl/2f8ep

Slachevsky. N. (2015). Una revolución neoliberal: la política educacional en Chile desde la dictadura militar. Educação e Pesquisa, vol. 41, número especial, pp. 1473-1486. https://doi.org/10.1590/S1517-9702201508141660

Torres-Vallejos, J. (2020). Efecto del rezago escolar de niños, niñas y adolescentes usuarios de programas psicosociales de infancia en su bienestar desde la perspectiva de la psicología positiva (tesis doctoral). Pontificia Universidad Católica de Valparaíso.

Valenzuela, J. P., Bellei, C. y De los Ríos, D. (2010). Segregación escolar en Chile. En S. Martinic y G. Elacqua (eds.). ¿Fin de ciclo? Cambios en la gobernanza del sistema educativo. Unesco.

Verger, A., Bonal X. y Zancajo. A. (2016). Recontextualización de políticas y (cuasi)mercados educativos. Un análisis de las dinámicas de demanda y oferta escolar en Chile. Archivos Analíticos de Políticas Educativas, vol. 24, núm. 27, pp. 1-27._http://dx.doi.org/10.14507/epaa.24.2098

Wang, T. \& Degol, J. (2015). School climate: A review of the construct, measurement, and impact on student outcomes. Educational Psychology Review, vol. 28, núm. 2, pp. 315-352. https://doi.org/10.1007/s10648-015-9319-1

Ziegler, S, Gessaghi, V. y Fuentes, S. (2018). Las propuestas curriculares en escuelas de elite en buenos aires: diferenciación institucional para educar en el privilegio. Página de Educación, vol. 11, núm. 2, pp. 40-60. https://doi. org/10.22235/pe.v11i2.1640 